\title{
Fibrosing alveolitis in infancy and childhood
}

\author{
C. J. HEWITT, D. HULL, AND JEAN W. KEELING \\ From the Department of Child Health, Nottingham University Hospital and Medical School, and \\ Department of Pathology, John Radcliffe Hospital, Oxford
}

SUMMARY Fibrosing alveolitis is a rare, diffuse lung disease characterized by varying combinations of two histological features: thickening of alveolar walls and the presence of large mononuclear cells in the alveolar spaces. Clinical details of 10 children with fibrosing alveolitis are reported. The main symptoms in children are tachypnoea or dyspnoea, cough, poor weight gain, and cyanosis. The condition is similar to that in adults, but it is usually a more acute illness, and if untreated, more predictably fatal. Respiratory failure, pulmonary hypertension, and cardiac failure are the major complications. Less commonly, superimposed bacterial infection and pneumothorax occur.

Chest $x$-rays often show a sequence of changes with a ground-glass appearance and fine mottling in the early stage of the disease, progressing to a picture of mainly hilar linear markings in those children who recover. The histological features at lung biopsy or necropsy are described; these correlated poorly with the radiological features, steroid responsiveness, and clinical course. Lung function tests in 3 older children showed evidence of markedly reduced lung volumes in 2 . Static lung compliance in 4 children in the acute stage of the illness was normal in 3 and diminished in one.

The response to steroid therapy was analysed in cases from the literature and the 10 reported cases. No spontaneous remissions occurred, all the survivors having been treated with corticosteroids. In children fibrosing alveolitis is almost always a corticosteroid-responsive disease. An appropriate course of prednisolone would be of at least 4 week's, but preferably of 8 weeks' duration, at a minimum daily dose of $2 \mathrm{mg} / \mathrm{kg}$. After improvement the steroid withdrawal should be cautious and protracted, comprising at least a year's continuous treatment.

Children rarely suffer from the condition which Hamman and Rich (1944) called 'acute' diffuse interstitial fibrosis of the lungs. Later reports of this condition detail a chronic process more appropriately described by terms like 'chronic diffuse fibrosis of the lungs', 'interstitial pneumonitis', and 'idiopathic pulmonary fibrosis'. Scadding (1964) proposed the term 'fibrosing alveolitis' to describe those progressive lung diseases characterized by varying combinations of two histological features: thickening of alveolar walls and the presence of large mononuclear cells in the alveolar spaces.

Liebow et al. (1965) observed intra-alveolar desquamation of large mononuclear cells in the lungs of patients suffering from a progressive lung disease and called the condition 'desquamative interstitial pneumonia' (DIP). It was implied that this group was different in pathogenesis from 'other forms of interstitial pneumonia', but Scadding and Hinson (1967) felt that the histological evidence for this

Received 5 April 1976 was equivocal. Since in many cases of pulmonary fibrosis the cause is unknown, Scadding (1970) suggested the term 'cryptogenic fibrosing alveolitis'.

More recently, Patchefsky et al. (1973) examined the clinical and pathological findings in 14 patients having the histological appearance of DIP. Necropsies on 3 of those patients showed diffuse pulmonary fibrosis with loss of the desquamative features noted at earlier biopsy. They concluded that the histological pattern recognized as DIP may be a nonspecific reaction to diverse forms of injury, not clearly separable from the usual type of diffuse interstitial pulmonary fibrosis. Fibrosing alveolitis, including DIP, is rare in childhood and published reports on the condition consist largely of single cases.

Over a 13-year period at The Hospital for Sick Children, Great Ormond Street, 24 children had a lung biopsy for diffuse lung disease. Only 8 were found to have fibrosing alveolitis. The histology of the lung in one infant with diffuse lung disease was normal. Nevertheless the clinical course was similar 
to that of the other children and a younger sib, also included, died aged 6 months when the lungs showed the characteristic pathology. In order to consolidate information on this rare disease, the clinical features of these 10 children are reported and they have been compared with those of 31 children with this condition previously reported in published reports in
English. The clinical details of Case 2 have already been reported (Liebeschuetz and Butler, 1965).

\section{Patients}

Brief clinical details of the 10 patients are given in Table 1.

Table 1 Clinical features of 10 patients with fibrosing alveolitis

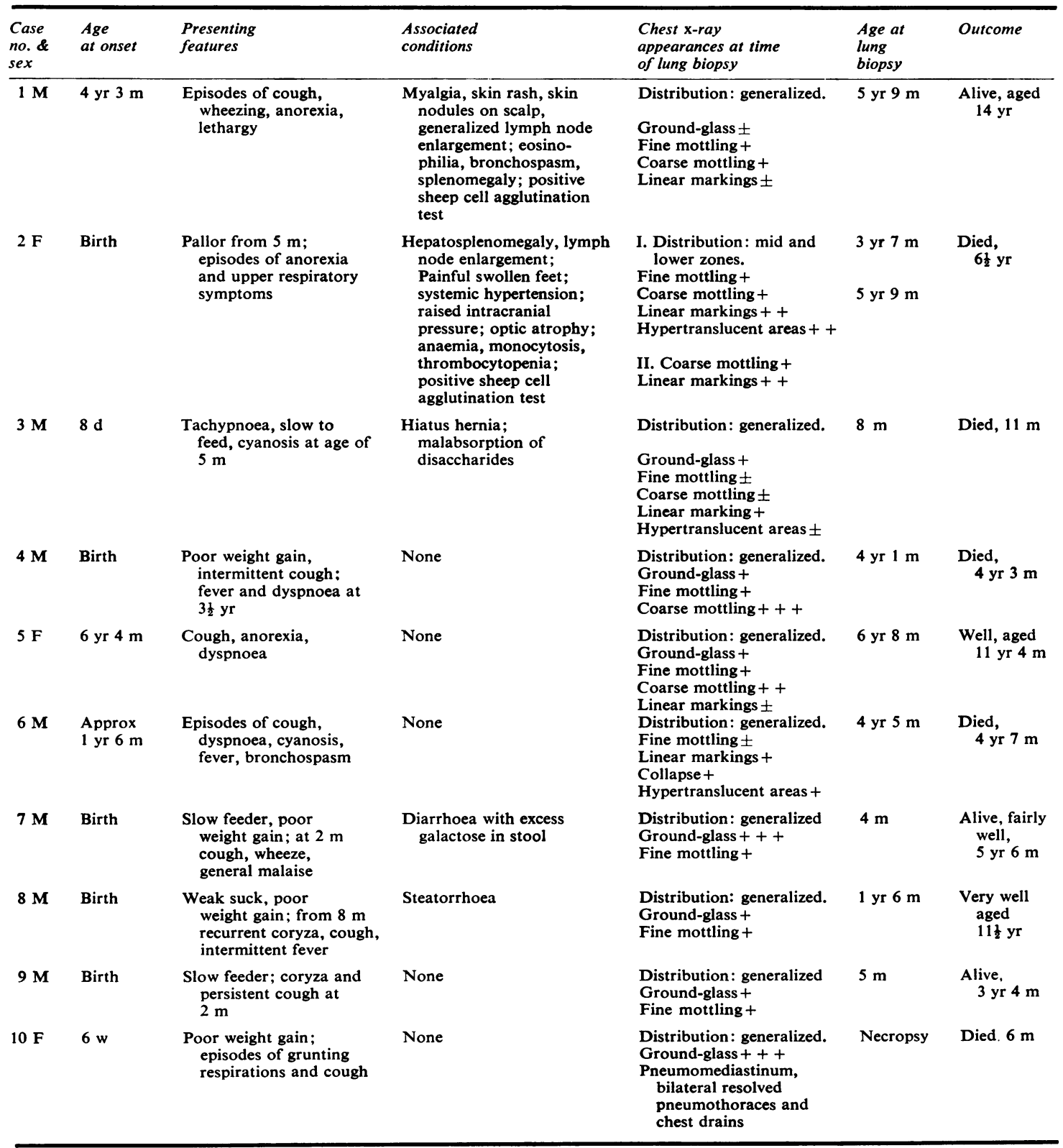




\section{Results}

Clinical features. The clinical features of fibrosing alveolitis are not diagnostic (Table 2). Of our 10 patients, 7 developed symptoms in the first year of life. All developed breathlessness with a cough; the majority (9) failed to thrive. At some stage the respiratory disorder was severe enough to cause cyanosis in 9 and prolonged enough to cause finger clubbing in 5 .

The disease led to a number of life-threatening complications (Table 3). Superimposed bacterial infections, as judged by fever, isolation of pathogen, and response to antibiotic therapy, were unusual. Respiratory failure was considered to be present if the $\mathrm{PaO}_{2}$ was $<60$ torr with the patient breathing air. Persistent central cyanosis in children in whom blood gas analysis was not made was taken as evidence of respiratory failure. It occurred in 9 out of 10 children in the early stages of the disease and was quickly fatal in one (Case 10) who also developed bilateral pneumothoraces. Pneumothorax also occurred.

Cardiac failure in a patient with chronic respiratory disease is frequently difficult to assess. Tachypnoea, tachycardia, and fluid retention are common to both and the jugular venous pulse is a difficult sign in small children. Therefore, two criteria were used to decide whether heart failure was present, an enlarging heart shown by chest $x$-ray and an increasing liver size. With this difficulty in mind, the use of digoxin has been recorded in a separate column. The complications in these 10 patients reflected their incidence in published reports. The immediate cause of death was cardiac failure with hypertension in one, and cardiorespiratory failure in the others.

Radiology. Chest $x$-rays were graded in severity from 0 to +++ for the following features: groundglass appearance, fine mottling $(<2 \mathrm{~mm})$, coarse mottling ( $>2 \mathrm{~mm}$ ), linear markings, and hyperlucent areas. Areas of collapse and consolidation were noted together with the presence of other features such as pneumothorax, effusions, and heart size. The radiological features were then correlated to the clinical course and corticosteroid therapy.

Early in the course of the disorder the chest $x$-ray usually showed a diffuse, bilateral ground-glass appearance with fine mottling. In those patients who survived, the chest $x$-ray showed a surprisingly consistent sequence of changes (Fig. 1). The early features of the ground-glass appearance and fine mottling (stage I) progressed to a mixed picture of fine and coarse mottling, sometimes associated with

Table 2 Clinical features of fibrosing alveolitis in 10 children

\begin{tabular}{|c|c|c|c|c|c|c|c|c|c|c|}
\hline & \multicolumn{10}{|c|}{ Case no. } \\
\hline & 1 & 2 & 3 & 4 & 5 & 6 & 7 & 8 & 9 & 10 \\
\hline Slow feeding & - & - & + & - & - & - & + & + & + & + \\
\hline Poor weight gain ( $<10$ th centile at presentation) & + & + & + & + & + & - & + & + & + & - \\
\hline Sputum & + & - & + & + & - & + & + & - & - & - \\
\hline Cough & + & + & + & + & + & + & + & + & + & + \\
\hline Recurrent episodes of bronchospasm & + & - & - & - & - & + & + & - & + & - \\
\hline Cyanosis & - & + & + & + & + & + & + & + & + & + \\
\hline Finger clubbing & + & + & - & + & - & - & + & + & + & - \\
\hline Fever & + & + & + & + & + & + & + & - & + & + \\
\hline Dyspnoea or tachypnoea & + & + & + & + & + & + & + & + & + & + \\
\hline \multicolumn{11}{|l|}{ Adventitiae } \\
\hline Râles & + & + & + & + & - & + & + & + & + & + \\
\hline Rhonchi & + & + & + & - & - & + & + & + & + & + \\
\hline
\end{tabular}

Table 3 Complications of fibrosing alveolitis in 10 children

\begin{tabular}{|c|c|c|c|c|c|c|c|c|c|c|}
\hline & \multicolumn{10}{|c|}{ Case no. } \\
\hline & $I$ & 2 & 3 & 4 & 5 & 5 & 6 & 7 & 8 & 10 \\
\hline Superimposed bacterial chest infection & + & - & - & - & - & - & + & - & - & - \\
\hline Respiratory failure & - & + & + & + & + & + & + & + & + & + \\
\hline Cardiac failure & - & + & - & + & - & + & + & + & - & - \\
\hline Digitilization & - & + & + & + & + & + & - & + & + & - \\
\hline Pulmonary hypertension (measured) & 0 & $\mathbf{0}$ & - & $\mathbf{0}$ & 0 & + & 0 & \pm & - & - \\
\hline Systemic hypertension & - & + & - & $t^{*}$ & - & - & - & $=$ & - & - \\
\hline Pneumothorax & - & - & - & - & + & - & - & - & - & + \\
\hline
\end{tabular}

*On corticosteroids.,+ present $;-$, absent; \pm , borderline; 0 , not measured. 


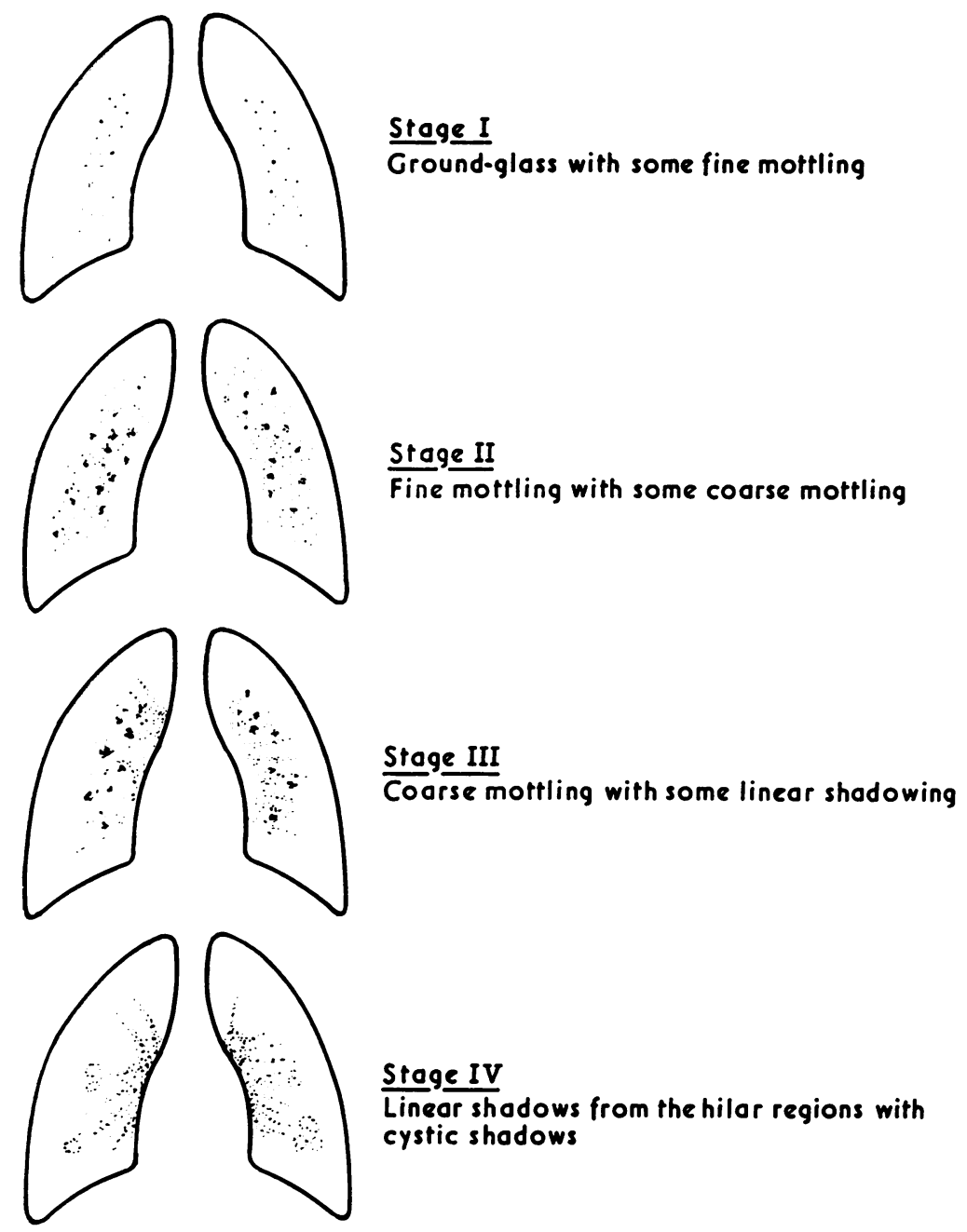

Fig. 1 Sequence of radiological change in fibrosing alveolitis is shown.

persistence of the ground-glass appearance, but to a lesser degree (stage II) (Fig. 2). As the disorder progressed and responded to treatment the groundglass appearance and fine mottling disappeared with the development of coarse mottling and the appearance of linear markings, usually perihilar (stage III) (Fig. 3). In 6 of 8 patients who developed these changes, cardiomegaly was also present. The endstage chest $x$-ray was characterized by varying degrees of linear shadowing commonly associated with hypertranslucent areas (stage IV) (Fig. 4). These hypertranslucent areas were particularly evident at the lung bases and when marked, resembled a honeycomb pattern. This feature was variable in its time of onset and was noted very early in one patient, within a few months of onset of symptoms. In the survivors this progression occurred over a 2- to 6-year period. Rapid progression from stage I to III in 3-4 months was occasionally noted.

Most frequently a generalized distribution of changes was present. In 3 patients, however, transient asymmetrical distribution was noted, with the right lung predominantly affected in 2 . There was often concentration of these early changes around the hilar regions. In one patient early changes were present in the middle and lower zones. Later the upper zones became involved with relative sparing of the bases (Case 2). In another (Case 1) the upper zones were spared. The linear markings were seen radiating from the hilar region, where this feature was usually most notable.

An equivocal pleural effusion was present in one 


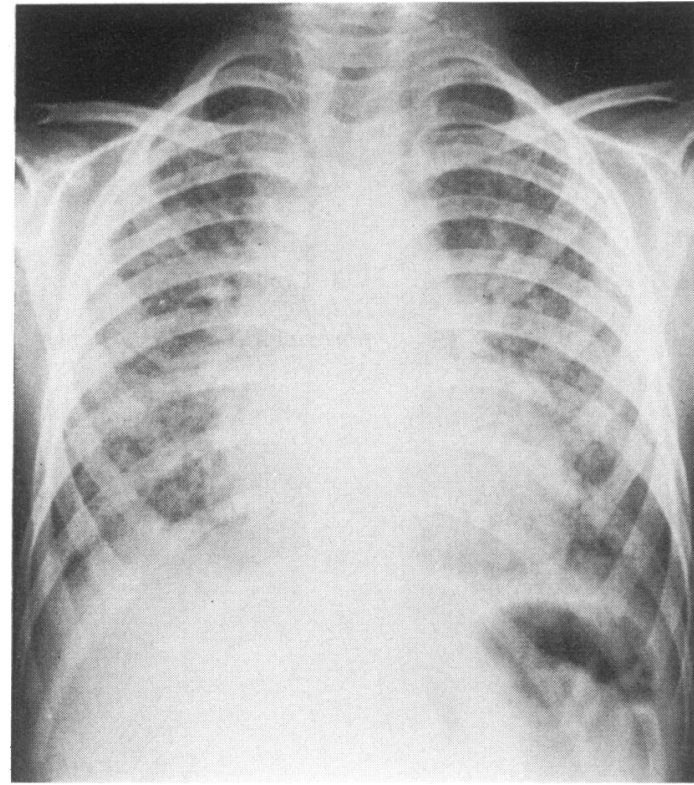

Fig. 2 Case 4. Chest x-ray taken 9 months after onset showing stage II changes.

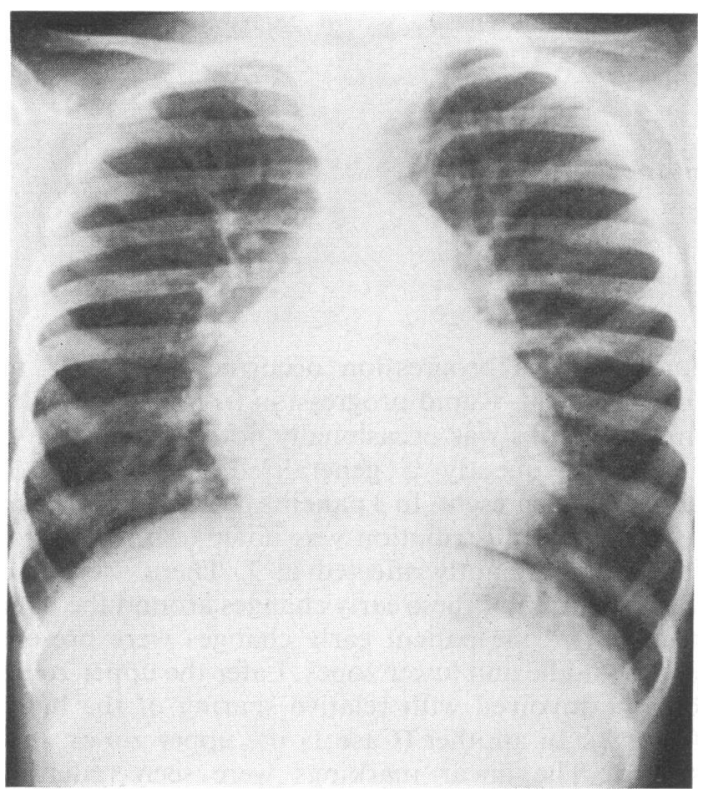

Fig. 3 Case 6. Chest X-ray taken 3 years after onset of symptoms showing stage III changes. Cardiomegaly is evident.

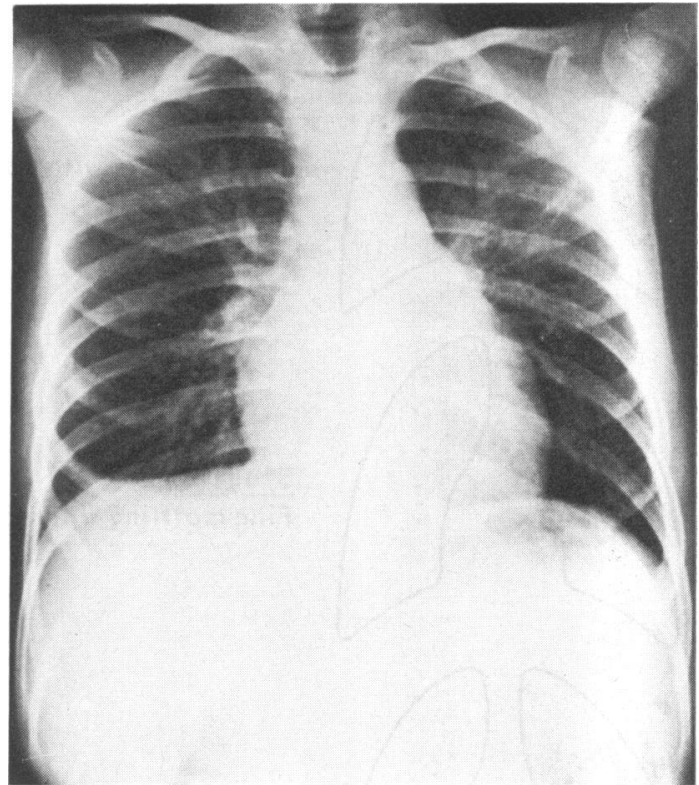

Fig. 4 Case 8. Chest $\mathrm{x}-$ ray taken 10 years after onset showing stage IV changes.

patient, and a small pneumothorax in 2, and extensive bilateral pneumothorax occurred in one patient (Case 10). Occasionally denser, poorly defined, frequently transient consolidated areas were seen. Areas of collapse were rare.

The late radiological features in those patients who died were variable in both grade and severity (Table 4). 4 of the 5 had mainly early features of moderate to severe degree. One patient (Case 2)

Table 4 Late radiological features in fatal cases of fibrosing alveolitis

\begin{tabular}{llll}
\hline Case no. & Stage & Degree & Cardiomegaly \\
\hline 2 & III-IV & Moderate & + \\
3 & I-II & Moderate & + \\
4 & II-III-IV & Moderate & + \\
6 & II-III & Moderate & + \\
10 & I & Severe; bilateral & - \\
& & pneumothoraces \\
\hline
\end{tabular}

+ , present; -, absent.

had mild stage III-IV changes. Cardiomegaly was present in all but one of those who died and was seen at some stage in the course of the illness in 2 of the 5 survivors.

Occasionally dramatic radiological 'improvement' was evident during steroid therapy. There was rapid clearing of the ground-glass appearance and 
Table 5 Lung function in 3 children with fibrosing alveolitis

\begin{tabular}{|c|c|c|c|c|c|c|}
\hline & \multicolumn{2}{|c|}{$\begin{array}{l}\text { Case } 5 \\
\text { Age } 6 \frac{1}{2} \mathrm{yr}, \text { ht. } 137 \cdot 8 \mathrm{~cm}, \\
\text { condition-very ill }\end{array}$} & \multicolumn{2}{|c|}{$\begin{array}{l}\text { Case } 7 \\
\text { Age } 5 \mathrm{yr}, \mathrm{ht} .102 \cdot 2 \mathrm{~cm}, \\
\text { condition-moderately ill }\end{array}$} & \multicolumn{2}{|c|}{$\begin{array}{l}\text { Case } 1 \\
\text { Age } 14 \mathrm{yr}, \mathrm{ht} .146 \mathrm{~cm}, \\
\text { condition-well }\end{array}$} \\
\hline & Patient & $\begin{array}{l}\text { Normal mean } \\
\pm 2 S D\end{array}$ & Patient & $\begin{array}{l}\text { Normal mean } \\
\pm 2 S D\end{array}$ & Patient & $\begin{array}{l}\text { Normal mean } \\
\pm 2 S D\end{array}$ \\
\hline $\begin{array}{l}\text { Peak expiratory flow rate }(1 / \mathrm{min}) \\
\text { Forced expiratory volume in }\end{array}$ & 55 & $285 \pm 90$ & 45 & $160 \pm 75$ & 260 & $325 \pm 95$ \\
\hline $\begin{array}{l}0.75 \mathrm{~s}(\mathrm{ml}) \\
\text { Forced vital capacity }(\mathrm{ml}) \\
\text { Functional residual capacity }(\mathrm{ml}) \\
\text { Thoracic gas volume }(\mathrm{ml})\end{array}$ & $\begin{array}{l}155 \\
205 \\
540\end{array}$ & $\begin{array}{l}1845 \pm 655 \\
2350 \pm 775 \\
1380 \pm 460\end{array}$ & $\begin{array}{l}370 \\
385 \\
760\end{array}$ & $\begin{array}{l}850^{*} \\
850^{*} \\
640^{*}\end{array}$ & $\begin{array}{l}1380 \\
2940 \\
2120 \\
3215\end{array}$ & $\begin{array}{l}2050 \pm 750 \\
2700 \pm 800 \\
1660 \pm 560 \\
1715 \pm 500\end{array}$ \\
\hline
\end{tabular}

*By extrapolation of data.

the fine and coarse mottling, but these features sometimes reappeared within 7 days of reducing or stopping corticosteroid therapy. This cycle of radiological improvement and deterioration was seen on at least 4 occasions in one patient (Case 7).

There was no clear correlation between the degree of intra-alveolar desquamation and the ground-glass, fine or coarse mottling appearance. Further, it was not possible to correlate the severity of mural thickening to the degree of linear markings on the $x$-ray.

Respiratory function tests. In 3 older children standard respiratory function tests requiring patient co-operation were made (Table 5). In Case 5, aged $6 \frac{1}{2}$, the studies were performed during the acute stage. There was gross reduction in lung volumes. Similar results were obtained in Case 7 when he was still symptomatic, 5 years after onset of the disease, when the chest $x$-ray showed stage II changes. On the other hand, Case 1, after a long illness, was asymptomatic when the tests were performed and his $x$-ray showed linear markings only. His lung volumes were high, but his Peak Flow Rate was low, suggesting the presence of obstructive airways disease.

In 4 children static lung compliance was measured as a preliminary investigation before open lung biopsy in the paralysed infant (Table 6). All the children were severely ill at the time of the test and it was therefore surprising to find that the static

Table 6 Lung function in 4 children with fibrosing alveolitis

\begin{tabular}{llll}
\hline & & \multicolumn{2}{l}{ Static compliance $\left(\mathrm{ml} / \mathrm{cmH}_{2} \mathrm{O}\right)$} \\
\cline { 3 - 4 } Case no. & Age & Patient & $\begin{array}{l}\text { Normal mean } \\
1 \mathrm{SD}\end{array}$ \\
\hline 9 & & & $3 \cdot 6 \pm 1 \cdot 6$ \\
3 & $5 \mathrm{~m}$ & $9 \cdot 4$ & $5 \cdot 6 \pm 1 \cdot 9$ \\
6 & $8 \mathrm{~m}$ & $7 \cdot 2$ & $15 \cdot 0 \pm 3 \cdot 1$ \\
5 & $4 \mathrm{yr} \mathrm{5} \mathrm{m}$ & $14 \cdot 8$ & $40 *$ \\
\hline
\end{tabular}

*By extrapolation of data. compliance was low in only one patient (Case 5), being normal or increased in the other 3 . The norma values were obtained using the same technique (A. D. Milner, personal communication, 1975). In these children dynamic compliance and total pulmonary resistance was measured using an oesophageal balloon and face mask connected to a pneumotachometer. Variable results were obtained supporting the clinical impression that bronchospasm makes a variable contribution to the respiratory difficulty.

Immunology. Studies were performed on 4 of the children to identify hypersensitivity or the presence of autoantibodies. In 2 the sheep cell agglutination test was positive, but apart from LE cells in one and thyroglobulin antibody in another, little positive was found. Serum immunoglobulin levels were variable. In the infants the IgA and IgG levels tended to be either low or normal, whereas IgM levels were normal or high. In one older patient, IgA, IgG, and IgM levels were normal or reduced, in the other 2 IgA and IgG levels were raised.

Histology. The histological changes at lung biopsy or necropsy in 10 infants are summarized in Table 7 in the manner of Scadding and Hinson (1967) and are graded according to the extent of desquamation of alveolar lining cells into the alveolar spaces in descending order. Cellular desquamation was seen in 9. In 2, it was very extensive and was the most prominent histological change (Fig. 5). Many alveolar spaces were completely obliterated by the desquamated cells. Many lymphoid follicles, with well developed germinal centres, were present in 5 biopsies (Fig. 6), some were peribronchiolar but others were seen throughout the biopsy, some being subpleural in position.

Thickening of the alveolar walls was present in all the biopsies. The thickening was prominent in 6 biopsies (Fig. 7) and slight in the other 3 (Fig. 8). There was histiocytic infiltration of the wall and an 
28 Hewitt, Hull, and Keeling

Table 7 Lung histology in 10 cases of fibrosing alveolitis

\begin{tabular}{|c|c|c|c|c|c|c|c|c|c|c|}
\hline \multirow{3}{*}{$\begin{array}{l}\text { Case } \\
\text { no. }\end{array}$} & \multicolumn{3}{|c|}{ Cells in alveoli } & \multirow{3}{*}{$\begin{array}{l}\text { Lymphoid } \\
\text { follicles }\end{array}$} & \multicolumn{6}{|c|}{ Mural thickening } \\
\hline & \multicolumn{2}{|c|}{ Large mononuclear } & \multirow[t]{2}{*}{ Other } & & \multirow{2}{*}{ Degree } & \multirow{2}{*}{$\begin{array}{l}\text { Histiocytic } \\
\text { infiltration }\end{array}$} & \multirow[b]{2}{*}{$\begin{array}{l}\text { Reticulin } \\
\text { fibres }\end{array}$} & \multirow[b]{2}{*}{$\begin{array}{l}\text { Collagen } \\
\text { fibres }\end{array}$} & \multirow[b]{2}{*}{$\begin{array}{l}\text { Elastic } \\
\text { fibres }\end{array}$} & \multirow{2}{*}{$\begin{array}{l}\text { Uniformity of } \\
\text { changes }\end{array}$} \\
\hline & Granular & Phagocytic & & & & & & & & \\
\hline $\begin{array}{l}1 \\
2\end{array}$ & +++ & + & $\mathbf{E}$ & + & Prominent & ++ & ++ & + & + & + \\
\hline (i) & +++ & + & E, L & + & Slight & + & ++ & + & - & + \\
\hline (ii) & - & - & & + & Slight & + & + & + & - & - \\
\hline Necropsy & ++ & + & & + & Slight & + & + & + & - & - \\
\hline 3 & ++ & + & & - & Prominent & + & +++ & ++ & + & + \\
\hline 4 & ++ & + & & - & Prominent & + & ++ & +++ & + & - \\
\hline 5 & ++ & + & $\mathbf{L}$ & + & Prominent & + & +++ & +++ & - & - \\
\hline $\begin{array}{l}10 \\
\text { (necropsy) }\end{array}$ & ++ & + & E, L & - & Moderate & ++ & + & + & + & - \\
\hline 6 & - & + & & - & Prominent & + & ++ & + & + & + \\
\hline 7 & -- & + & & - & Slight & + & ++ & ++ & - & + \\
\hline 8 & - & + & & - & Prominent & + & ++ & ++ & - & + \\
\hline 9 & - & - & - & - & - & - & - & - & - & + \\
\hline
\end{tabular}

+++ , gross; ++ , marked; + , present; -, absent.

E, eosinophil granulocyte; L, lymphocyte.

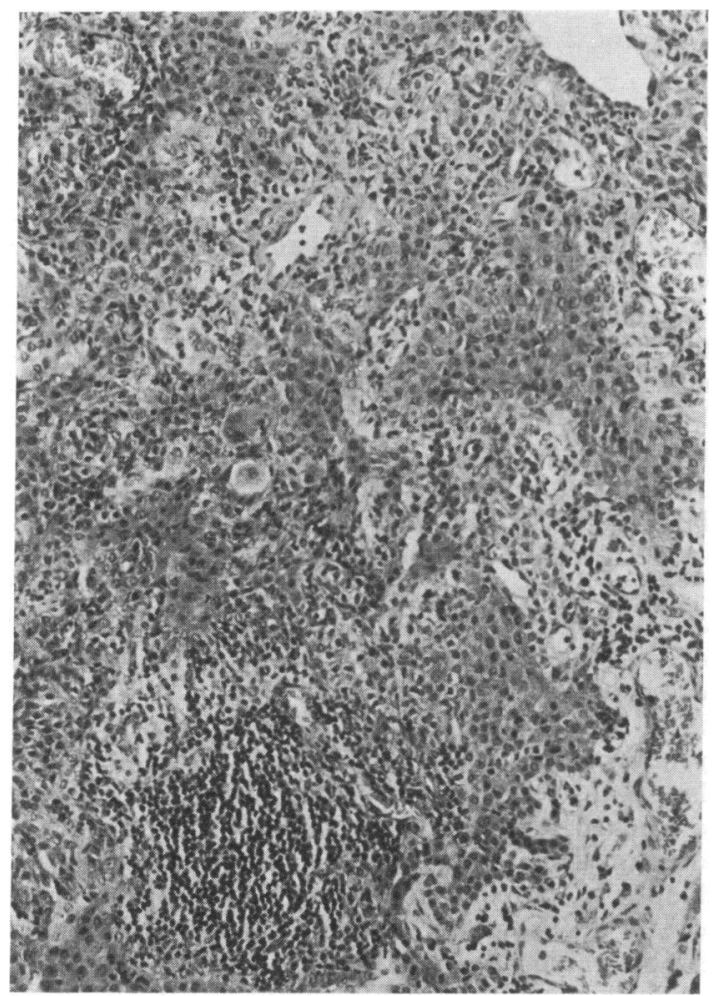

Fig. 5 Case 2 ( $i$, see Table 7). Gross desquamation of alveolar lining cells completely fills many of the alveoli. (Haematoxylin-eosin. $\times 28$.)

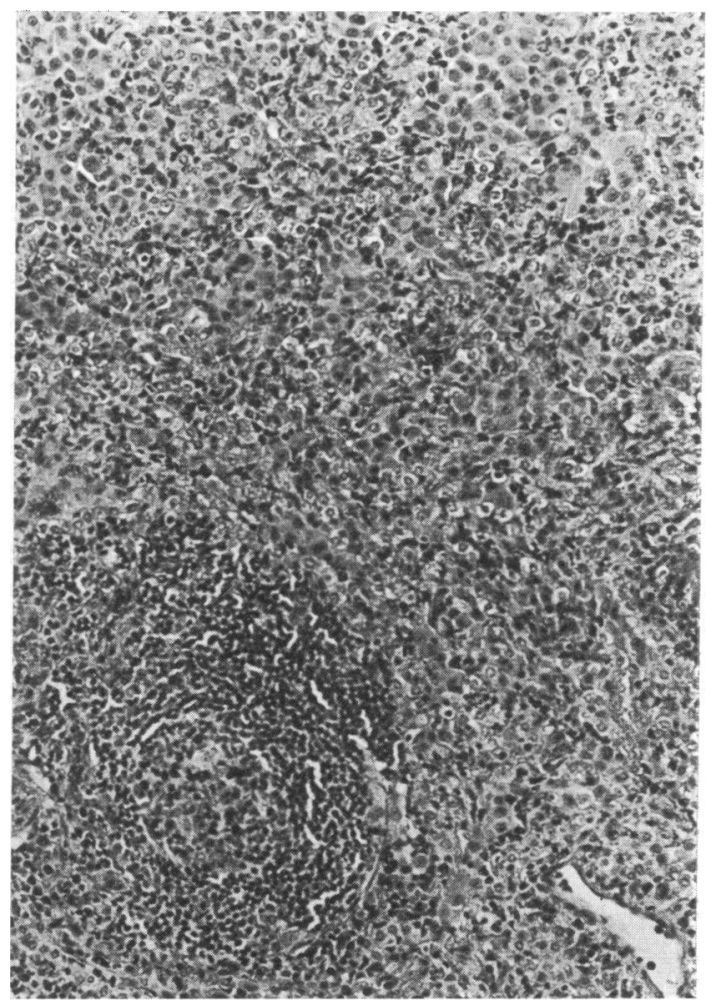

Fig. 6 Case 1. A lymphoid follicle with a prominent germinal centre is seen in a biopsy having gross cellular desquamation (H.E. $\times 28$.) 


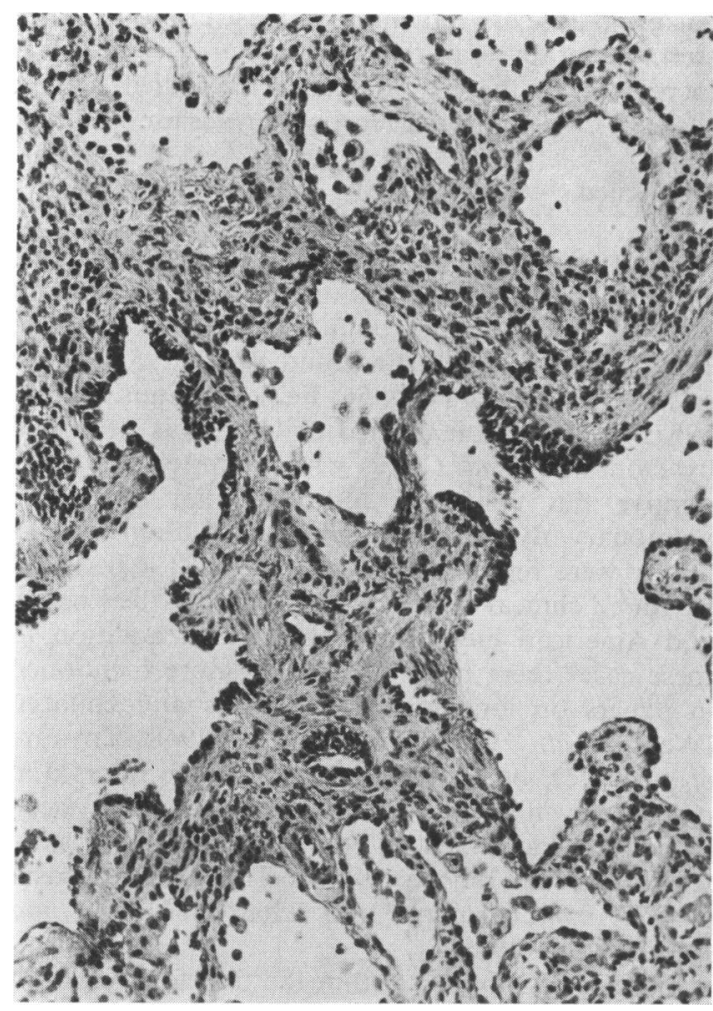

Fig. 7 Case 8. Prominent mural thickening is seen, accompanied by little cellular desquamation. Histiocytic infiltration and collagen deposition contribute to the thickening of the wall. (Haematoxylin-Van Gieson. $\times 28$.)

increase in reticulin and collagen fibres. In 4 biopsies, excessive amounts of elastic tissue were present. The severity of mural thickening did not correlate well with the extent of cellular desquamation. Mural thickening was uniformly distributed in 6 biopsies and of variable severity in the other 3 , though changes were widespread. The severity of the thickening bore little relationship to the uniformity of the distribution.

Blocks of lung tissue obtained at necropsy from Case 2 showed desquamation of both granular and phagocytic cells into the alveoli and lymphoid follicles and slight fibrosis. The mural thickening was not uniform. In addition, overdistension of alveoli was widespread and atheromatous changes were present in large and medium sized pulmonary arteries. Post-mortem lung sections from Case 10 showed patchy, moderately severe thickening of the alveolar walls due to cellular infiltration and the presence of reticulin, collagen, and elastic fibres. In these areas mononuclear cells and eosinophil

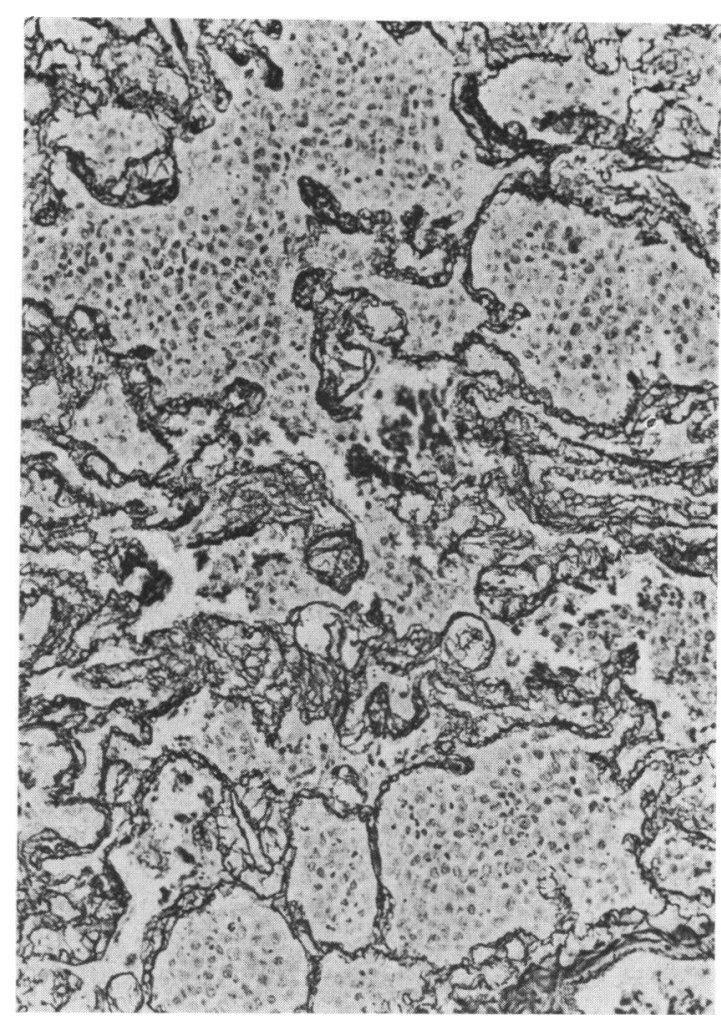

Fig. 8 Case 2 (i, see Table 7). Slight mural thickening with filling of alveolar spaces by desquamated cells.

(Gordan and Sweet's method for reticulin. $\times 28$.)

polymorphs were seen within the alveoli (Fig. 9). Intervening lung had minimal mural thickening and there was some overdistension of alveoli.

Steroid therapy. Analysis of effects of corticosteroid therapy is given in Table 8 . All but 2 children improved on corticosteroids. Case 5 received treatment with corticosteroids and tetracosactrin. Improvement coincided with discontinuation of hydrocortisone treatment which had been given to 'cover' the period of the lung biopsy. Case 10 had had treatment for only 3 days. The time taken before definite improvement was noted varied from as little as 5 days to 6 weeks. The effective daily dose of prednisolone was as little as $0.53 \mathrm{mg} / \mathrm{kg}$ in one patient and as much as $5.5 \mathrm{mg} / \mathrm{kg}$ in another. The dose on which clinical or radiological deterioration occurred was difficult to assess, since several changes of dose were often made in a short space of time. Deterioration occurred at a daily dose of $0.36 \mathrm{mg} / \mathrm{kg}$ of prednisolone in one patient and on $2 \mathrm{mg} / \mathrm{kg}$ in another, and was noted as early as 4 days after a reduction in corti- 


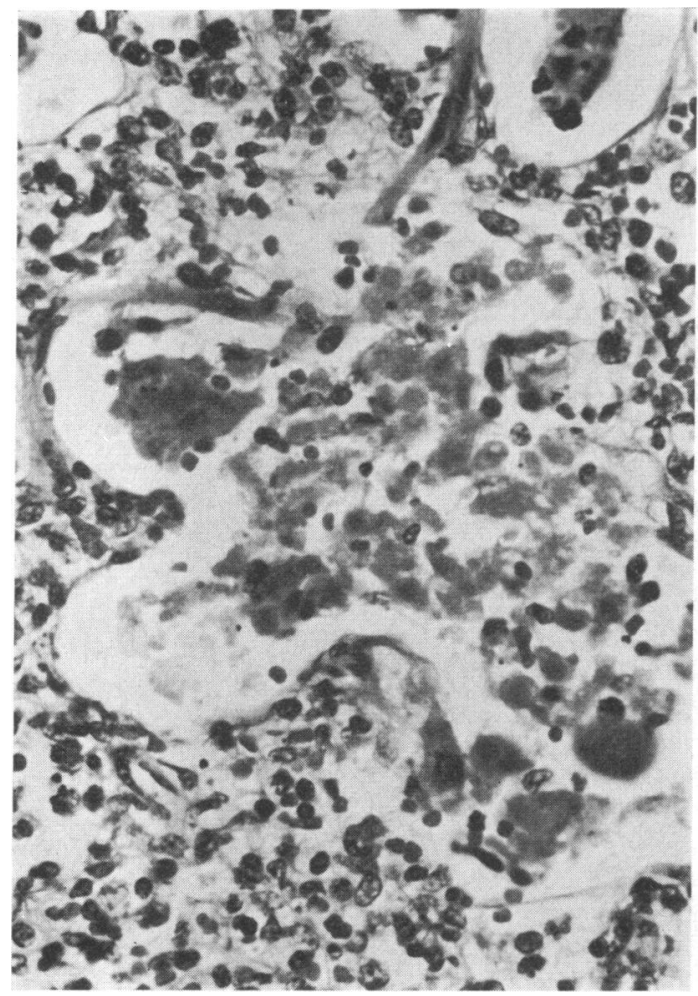

Fig. 9 Case 10. Mononuclear cells and eosinophil polymorphs are seen within the alveolus. $(\times 340$. costeroid dose in 6 patients. 5 of these improved when steroid therapy was reintroduced or the dose was increased. Of the 10 patients, 5 have died. Of the survivors, 4 have been off corticosteroids for 1-6 years.

\section{Discussion}

Previous published reports of fibrosing alveolitis. In 1956-57 there were a number of clinical reports of children with interstitial pulmonary fibrosis (Bradley, 1956; Aranson, 1956; Baar and Braid, 1957; Grant et al., 1956; Donohue, 1956; Feinerman and Harris, 1957). A family of affected children was described by Donohue et al. (1959) who preferred the descriptive but confusing term 'familial fibrocystic pulmonary dysplasia'. 2 affected children in one family were reported by Mann $(1959,1965)$. In all we found clinical details of 31 patients in the English and American literature (Table 9). In addition to these cases there have been many more mentioned in papers on lung biopsy in infants and children (Weng et al., 1968; Stringer et al., 1968; Toyama et al., 1971), but not reported in detail. Interstitial pulmonary fibrosis in childhood has also been extensively described in the European literature which includes reports by Vaněk (1954), Kubašta et al. (1958), Kapanci and Chauvet (1967), and Radice et al. (1969).

Onset of symptoms within the first few weeks of life was unusual. Tan et al. (1974) described a term infant who developed symptoms of respiratory

Table 8 Corticosteroid therapy in 10 children with fibrosing alveolitis

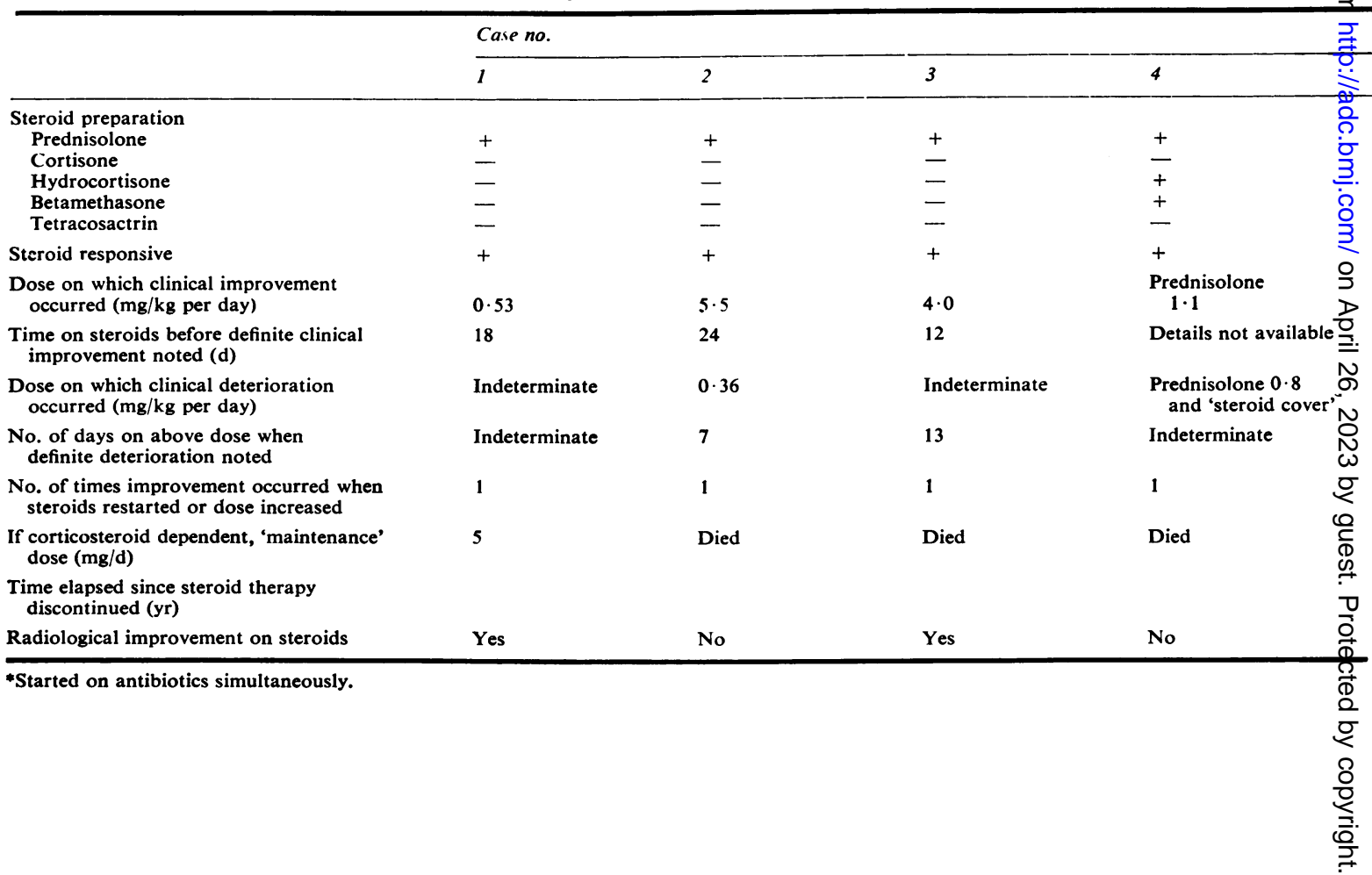


distress with cyanosis within a few minutes of birth, eventually dying in respiratory failure at $5 \frac{1}{2}$ months. In no other case did symptoms develop so dramatically and so early. Of the 31 published cases reviewed (see Table 9), 19 developed respiratory symptoms within the first year of life. Of this latter group 3 were alive at the time of reporting, though in 2 the follow-up period was very short. The mean survival period of this group was approximately 4.7 months. Of the 12 cases who presented over one year of age, 5 were alive at the time of reporting and had survived for a period of from 6 months to 14 years. In this second group the mean survival time of those who had died naturally by the time of reporting was approximately 6 years.

There appear to be no cases of spontaneous remission of the condition in this group of 31 children; all the survivors were treated with corticosteroids. Cyanosis was present in 27 of the 31 patients reviewed. Pulmonary artery pressure was measured in 4 and was definitely raised in one. Electrocardiographic or post-mortem evidence of right ventricular hypertrophy was found in 14 children. Cardiac failure was recorded in 11 patients, all but 3 of whom were digitalized. Systemic blood pressure was normal in 7 patients in whom it was recorded. In only 2 cases was there good evidence for a superimposed bacterial infection. Spontaneous pneumothorax complicated 4 cases and in that reported by Aranson (1956) it appeared to contribute significantly to the patient's death.
Comparison between fibrosing alveolitis in children and adults. It is instructive to compare the clinical features of fibrosing alveolitis in children with those in adults. Large series of patients with interstitial pulmonary fibrosis in adults have been reported (Livingstone et al., 1964) and the literature reviewed (Rubin and Lubliner, 1957; Turner-Warwick, 1971/72). In adults the male : female ratio is $1 \cdot 8: 1$; in children it is $1: 1 \cdot 1$. Finger clubbing was found to occur in about $60 \%$ of adults and was present in $34 \%$ of children. Widespread crepitations occur in more than $90 \%$ of adults with fibrosing alveolitis. $54 \%$ of children had crepitations at some stage during their illness. 37 of the $\mathbf{4 5}$ patients in the series of Livingstone et al. (1964) had coughs, compared with $83 \%$ of children. $66 \%$ of children had poor weight gain. In Livingstone's series there was reported weight loss in $56 \%$.

Dyspnoea or tachypnoea, two of the most constant features in adult patients with fibrosing alveolitis, was present in all of our patients and in virtually all of the other reported cases in children. Cyanosis at rest was reported at some stage in about half of Livingstone's series and was usual in the terminal stages. Cyanosis was present in all but one of our patients and in only one of these was it a very late feature. It is important to emphasize, however, that our series is rather different in that all but one had lung biopsies, and the severe progressive nature of the condition in each case was itself one of the important indications for lung biopsy. As in the

\begin{tabular}{|c|c|c|c|c|c|}
\hline 5 & 6 & 7 & 8 & 9 & 10 \\
\hline+ & + & + & - & + & - \\
\hline - & - & - & + & - & - \\
\hline+ & - & - & - & - & + \\
\hline- & - & - & - & - & - \\
\hline+ & - & - & - & - & - \\
\hline - & + & + & + & + & Had only 3 days \\
\hline \multirow[t]{5}{*}{$\begin{array}{l}\text { [mproved after stopping } \\
\text { steroids }\end{array}$} & $2 \cdot 4$ & $2 \cdot 0$ & Cortisone 14 & $8 \cdot 3$ & \\
\hline & 6 & 5 & $30-42$ & $2 *$ & \\
\hline & $1 \cdot 6$ & 0 & & $2 \cdot 0$ & \\
\hline & 4 & Indeterminate & & 7 & \\
\hline & 0 & 3 & & 4 & \\
\hline Jff steroids & Died & Off steroids & Off steroids & Off steroids & Died \\
\hline H & & 1 & 6 & 3 & \\
\hline Yes & No & Yes & Yes & Yes & No \\
\hline
\end{tabular}


32 Hewitt, Hull, and Keeling

Table 9 Clinical details of 31 published cases of fibrosing alveolitis in childhood

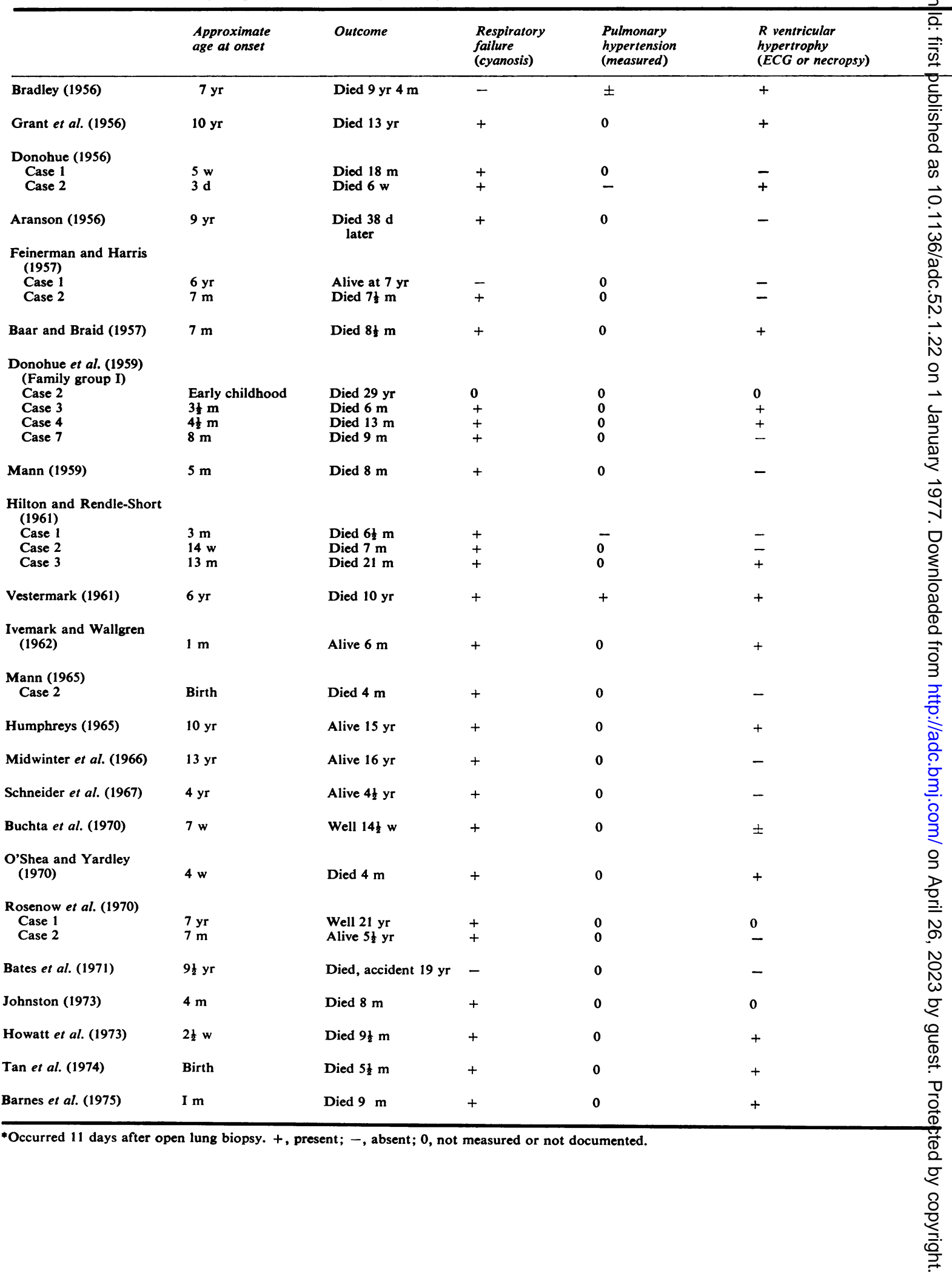




\begin{tabular}{|c|c|c|c|c|c|}
\hline $\begin{array}{l}\text { Cardiac } \\
\text { failure }\end{array}$ & Digitalization & $\begin{array}{l}\text { Systemic } \\
\text { hypertension }\end{array}$ & Infection & Pneumothorax & Fever \\
\hline+ & + & - & - & - & + \\
\hline- & - & - & - & - & - \\
\hline- & $\overline{-}$ & $\begin{array}{l}\mathbf{0} \\
\mathbf{0}\end{array}$ & $\overline{-}$ & $\underline{-}$ & + \\
\hline - & + & 0 & - & + & + \\
\hline$\overline{-}$ & - & - & - & - & + \\
\hline - & - & 0 & - & - & + \\
\hline+ & + & 0 & + & - & + \\
\hline $\mathbf{0}$ & 0 & 0 & 0 & + & 0 \\
\hline \pm & + & $\mathbf{0}$ & - & - & - \\
\hline$\overline{-}$ & $\overline{-}$ & $\begin{array}{l}0 \\
0\end{array}$ & $\bar{t}$ & $\overline{-}$ & $\overline{+}$ \\
\hline+ & - & 0 & - & - & + \\
\hline \pm & \pm & $\mathbf{0}$ & - & - & + \\
\hline$\overline{+}$ & $\overline{+}$ & $\begin{array}{l}0 \\
0\end{array}$ & $\overline{-}$ & $\overline{-}$ & $\begin{array}{l}+ \\
+\end{array}$ \\
\hline+ & + & - & - & - & - \\
\hline - & + & 0 & - & + & + \\
\hline 0 & - & 0 & - & - & - \\
\hline- & - & - & - & - & - \\
\hline- & - & $\mathbf{0}$ & - & - & - \\
\hline- & - & - & - & - & - \\
\hline - & - & - & - & - & + \\
\hline+ & + & $\mathbf{0}$ & - & - & - \\
\hline - & - & $\mathbf{0}$ & - & - & - \\
\hline - & - & $\mathbf{0}$ & - & - & + \\
\hline- & - & $\mathbf{0}$ & - & - & - \\
\hline+ & - & 0 & - & - & - \\
\hline+ & - & 0 & - & $+*$ & - \\
\hline- & - & 0 & - & - & 0 \\
\hline+ & + & $\mathbf{0}$ & - & - & - \\
\hline
\end{tabular}


literature on fibrosing alveolitis in adults, fever has been a prominent feature of the condition in our series, and this did not always appear to indicate the presence of a superimposed bacterial respiratory infection. Many children with fibrosing alveolitis reported in the literature have had a pyrexia during the illness (Table 9). Essentially then, the clinical features in children and adults with fibrosing alveolitis are very similar but it is probably fair to say that in children it is usually a more acute illness and, if untreated, more predictably fatal.

\section{Complications}

Infection. The incidence of superimposed bacterial infection is low and in only 2 children reviewed (Baar and Braid, 1957; Donohue, 1956) did there seem good evidence of this. 3 of the 4 cases reported by Hamman and Rich (1944) had mucopurulent sputum and 1 of these had pulmonary tuberculosis. Bacterial infection in these cases may have been largely responsible for the more acute course of the condition. Turner-Warwick $(1971 / 72)$ states that bronchial infection may occur, particularly in advanced cases in which obstruction is also present.

Bronchospasm. Two of the 4 children in our series who had evidence of recurrent episodes of bronchospasm also had convincing features of superimposed bacterial infection. In these 2 patients 1 had no family history of atopy (Case 7) and the father of the other (Case 6) was an asthmatic. Of the remaining 8 patients there was a definite family history of atopy in 1 (Case 4).

Haematological features. Persistent eosinophilia (noted in Case 1) has previously been reported in adult patients with fibrosing alveolitis and their relatives (Bonanni et al., 1965). Eosinophilia in children with this condition has been noted by Johnston (1973), Buchta et al. (1970), and Donohue (1956). The persistent monocytosis in Case 2 was never explained, though the thrombocytopenia was thought to be secondary to the splenomegaly.

Gastrointestinal. The steatorrhoea and presumed disaccharide intolerance seen in Case 3 was never explained though a jejunal biopsy was not done. Coexisting diffuse pulmonary fibrosis and coeliac disease have been described (Hood and Mason, 1970). Malabsorption might be explained on the basis of chronic portal venous congestion and hypoxia. In Case 7 there was no improvement of the diarrhoea on the disaccharide-free diet but this did occur concurrently with the improvement in the respiratory symptoms.
Aetiology. It seems possible that fibrosing alveolitis is the pathological expression of an abnormal response of the patient to a variety of stimuli. In some patients there is a strong family history. Donohue et al. (1959) reviewed the family history of children with pulmonary fibrosis and concluded that in those families with more than one member affected it was transmitted as a dominant gene with reduced penetrance.

Hughes (1964) described 3 affected members of one family and reviewed evidence of the familial nature of interstitial pulmonary fibrosis. 2 of our patients were sibs. The inherited abnormality might lie in the immunological response. The immunopathological processes in fibrosing alveolitis are of interest also in view of the concurrence of a number of diseases of unknown aetiology, such as rheumatoid arthritis, chronic active hepatitis, ulcerative colitis, thyroid disease, and systemic lupus erythematosus, all frequently characterized by the presence of nonorgan-specific autoantibodies, which may also be present in fibrosing alveolitis occurring alone (Turner-Warwick, 1968). Deposits of IgG, IgM, and the third complement (C3) have been shown in the alveolar walls of lung biopsies from cases of fibrosing alveolitis, mainly confined to regions without extensive fibrosis (Nagaya et al., 1973). However, Poon et al. (1973) were unable to show any $\operatorname{IgG}, \operatorname{IgA}$, or $\operatorname{IgM}, \mathrm{C} 3$, or fibrinogen in their case and concluded that this could be explained by the timing of the biopsy in relation to the course of the disease, or to variable aetiology. Evidence of involvement of the immunological system in the pathogenesis of fibrosing alveolitis has been reviewed by McCombs (1972). Hobbs and Turner-Warwick (1967) found that one or more classes of immunoglobulins were increased above normal in 21 of 32 adult patients with fibrosing alveolitis. In the older children in this series the immunoglobulin levels also tended to be high, but in the infants they tended to be low or normal, suggesting an inadequate or inappropriate response. However, some of these values were obtained while the infants were on steroid therapy and are therefore difficult to interpret.

The insults which lead to widespread pulmonary fibrosis have been reviewed by Turner-Warwick (1974). In none of our cases was there a definite history of exposure to drugs, organic or inorganic dusts likely to cause pulmonary fibrosis. Diffuse pulmonary fibrosis may occur in patients with pulmonary venous obstruction (Andrews, 1957) and it is interesting to note that this was seen in the infant reported by Diamond (1958). Severe pulmonary infection resulting in widespread inflammatory exudates may progress to pulmonary fibrosis. 
Whitcomb et al. (1970), in a well documented report on a 34-year-old male, describe generalized fibrosis after a Pneumocystis carinii infection. In the case reported by Baar and Braid (1957) the respiratory illness began with whooping cough at the age of 7 months. A similar occurrence in a 10-year-old boy has been reported by Zaręba and Pyda (1966). There is some evidence that viral infections might precipitate the initial illness (O'Shea and Yardley, 1970). The clinical features suggested this possibility in Case 10 in this series.

Steroid therapy. Although all but 2 of our patients did improve on corticosteroids, it must be emphasized that it was sometimes difficult to be sure whether this could be attributed to concurrent treatment for a presumed respiratory infection, the corticosteroids, or perhaps a natural remission.

In the literature on adult interstitial pulmonary fibrosis an adequate dose of prednisolone is considered to be $30-40 \mathrm{mg} / \mathrm{d}$. Scadding and Hinson (1967) found that all their patients who responded did so on a daily dose of $30 \mathrm{mg}$ prednisolone. The symptoms in one patient reported in the series by Livingstone $e$ t al. (1964) were only controlled by prednisolone $40 \mathrm{mg}$ daily. Similar and sometimes larger doses of corticosteroids have been reported for children (Rosenow, et al., 1970; Schneider et al., 1967). However, in most of these reports it is difficult to assess whether such a high initial dose was really necessary, and this criticism applies equally to the 10 patients described here.

It is possible to get a clear idea of an 'adequate' dose of corticosteroids from that dose on which some patients relapsed. One patient clearly deteriorated on prednisolone $1.5 \mathrm{mg} / \mathrm{kg}$ per day (Case 6), and another (Case 9) on $2 \mathrm{mg} / \mathrm{kg}$ per day (Table 8). It seems reasonable therefore that the starting dose of prednisolone should be at least $2 \mathrm{mg} / \mathrm{kg}$ per day. In view of the possibility of coexisting malabsorption, parenteral administration of corticosteroids ought to be considered if the patient fails to improve on oral therapy.

There is differing opinion in the literature as to the recommended duration of steroid therapy. An editorial in the British Medical Journal (1972) recommended a starting dose of prednisolone of $30-45 \mathrm{mg} / \mathrm{d}$ for 1 or 2 weeks, followed by a 'quite rapid' dose reduction to $10 \mathrm{mg} / \mathrm{d}$. In the series of adult cases reported by Stack et al. (1972) prednisolone was usually given at a daily dose of $20-40 \mathrm{mg}$ for a period of from 2-8 weeks, after which it was either stopped or reduced to a daily maintenance dose of 5-10 mg. In our series all of the children who improved on corticosteroid therapy did so within 6 weeks of starting treatment, but in 3 of these im- provement was not noted until the third to sixth week of treatment. In the case of the 13-year-old boy reported by Midwinter et al. (1966), who was initially treated with prednisolone $10 \mathrm{mg}$ twice daily for 3 months, improvement was noted only after 2 months of therapy. Thus a fair trial of steroid therapy in children would be of at least 4 weeks' duration and preferably 8 weeks. Rosenow et al. (1970) emphasize that the duration of treatment has to be individualized according to the response obtained, but for desquamative interstitial pneumonia recommended at least a 1-year and preferably a 2-year course of steroid therapy. Our results support their advice that withdrawal of steroids should be cautious and protracted.

Livingstone et al. (1964) feel that treatment with steroids is not indicated for those asymptomatic patients with the chronic form of the disease, or for those in whom the symptoms were static or only slowly progressive. None of our patients could be included in this category. They also make the point that though the presence of pulmonary fibrosis on lung biopsy might be considered unfavourable, it cannot be assumed that more acute lesions are not present and therefore treatment with steroids should not be withheld on this score. Correlation of biopsy histology and steroid responsiveness in our series certainly seems to bear out this point.

In lung biopsies from their patients, Scadding and Hinson (1967) found an inverse relation between the amounts of cellular desquamation into the alveoli and the degree of alveolar wall thickening. They also showed a relation between slight thickening of the wall and the uniformity of changes within the biopsy specimen, though drawing attention to the small size of the sample compared with lung volume. We were unable to find such good correlation between these parameters, though the presence of lymphoid follicles was associated with prominent cellular desquamation. This may be due to poor sampling or indicate a different course of the disease in children. They also found that steroid therapy suppressed symptoms and signs in a few of the patients whose biopsy showed only slight alveolar wall thickening and many intra-alveolar mononuclear cells, but in none of those with much thickened alveolar walls. In addition, they found no relationship between histology at time of biopsy and total duration of the disease from onset to death. There is no such correlation in this series. It is questionable whether the postoperative deterioration in Case 4 was due to the stress of the open lung biopsy, but it seems advisable that large doses of steroid 'cover' should be used in these patients when undergoing major surgery.

In view of the effect of steroids, it is not surprising 
that immunosuppressive therapy has been tried. Brown and Turner-Warwick (1971) reported 5 patients with fibrosing alveolitis who had been treated in this way. A useful response was obtained in 3.2 of these had already improved on steroids, but because of important side effects while on maintenance therapy, immunosuppressives were used. This treatment maintained the clinical improvement and at the same time allowed a significant reduction in the steroid dosage. The third patient responded to immunosuppressant treatment only. Patients with advanced fibrotic but progressive disease who had not responded to corticosteroid treatment failed to improve on immunosuppressant therapy. Azathioprine was used initially but cyclophosphamide was used later in one and chlorambucil in another. Bates et al. (1971) reported an 11-yearold with desquamative interstitial pneumonia who only improved when given a 6-week course of cyclophosphamide in addition to $60 \mathrm{mg}$ of prednisolone daily. Barnes et al. (1975) described an infant with fibrosing alveolitis who failed to respond to an adequate dose of oral prednisolone and azothioprine and died at 9 months of age. Cyclophosphamide was used in only one of this series (Case 3) and had no apparent benefit, though this was tried rather late in the course of the condition.

We thank Prof. J. Soothill for help with interpreting immunoglobulin values; physicians at The Hospital for Sick Children, Drs. R. E. Bonham-Carter, P. R. Evans, A. P. Norman, and E. N. Hey for permission to publish details of patients under their care; Dr. C. J. E. Wynne-Williams for permission to publish details of his patient (Case 10); and Miss Shelagh Roberts for typing the manuscripts.

\section{References}

Andrews, E. C. (1957). Five cases of an undescribed form of pulmonary interstitial fibrosis caused by obstruction of the pulmonary veins. Bulletin of the Johns Hopkins Hospital, 100, 28-40.

Aranson, A. (1956). Hamman-Rich syndrome. Journal of the Maine Medical Association, 47, 105-107.

Baar, H. S., and Braid, F. (1957). Diffuse progressive interstitial fibrosis of the lungs in childhood. Archives of Disease in Childhood, 32, 199-207.

Barnes, S. E., Godfrey, S., Millward-Sadler, G. H., and Roberton, N. R. C. (1975). Desquamative fibrosing alveolitis unresponsive to steroid or cytotoxic therapy. Archives of Disease in Childhood, 50, 324-327.

Bates, D. V., Macklem, P. T., and Christie, R. V., (1971). Desquamative histiocytic interstitial pneumonitis. Respiratory Function in Disease, 2nd ed., p. 272. Saunders, Philadelphia.

Bonanni, P. P., Frymoyer, J. W., and Jacox, R. F. (1965). A family study of idiopathic pulmonary fibrosis. American Journal of Medicine, 39, 411-421.
Bradley, C. A. (1956). Diffuse interstitial fibrosis of the lungs in children. Journal of Pediatrics, 48, 442-450.

British Medical Journal (1972). (Editorial.) Steroid drugs in chest disease, 2, 459-460.

Brown, C. H., and Turner-Warwick, M. (1971). The treatment of cryptogenic fibrosing alveolitis with immunosupressant drugs. Quarterly Journal of Medicine (New Series), 40, 289-302.

Buchta, R. M., Park, S., and Giammona, S. T. (1970). Desquamative interstitial pneumonia in a 7-week-old infant. American Journal of Diseases of Children, 120, 341-343.

Diamond, I. (1958). The Hamman-Rich syndrome in childhood. Report of a case with unilateral pulmonary arterial and venous stenosis and atriovenous occlusion. Pediatrics, 22, 279-288.

Donohue, W. L. (1956). Interstitial plasma cell pneumonia. Laboratory Investigation, 5, 97-105.

Donohue, W. L., Laski, B., Uchida, I., and Munn, J. D. (1959). Familial fibrocystic pulmonary dsyplasia and its relation to the Hamman-Rich syndrome. Pediatrics, 24, 786-813.

Feinerman, B., and Harris, L. E. (1957). Unusual interstitial pneumonitis. Report of two cases occurring in children. Proceedings of the Staff Meetings of the Mayo Clinic, 32, 637-640.

Grant, I. W. B., Hillis, B. R., and Davidson, J. (1956). Diffuse interstitial pulmonary fibrosis. American Review of Tuberculosis and Pulmonary Diseases, 74, 485-510.

Hamman, L., and Rich, A. R. (1944). Acute diffuse interstitial fibrosis of the lungs. Bulletin of the Johns Hopkins Hospital, 74, 177-204.

Hilton, H. B., and Rendle-Short, J. (1961). Diffuse progressive interstitial fibrosis of the lungs in childhood (HammanRich syndrome). Archives of Disease in Childhood, 36, 102-106.

Hobbs, J. R., and Turner-Warwick, M. (1967). Assay of circulating immunoglobulins in patients with fibrosing alveolitis. Clinical and Experimental Immunology, 2, 645-652.

Hood, J., and Mason, A. M. S. (1970). Diffuse pulmonary disease with transfer defect occurring with coeliac disease. Lancet, 1, 445-447.

Howatt, W. F., Heidelberger, K. P., LeGlovan, D. P., and Schnitzer, B. (1973). Desquamative interstitial pneumonia. American Journal of Diseases of Children, 126, 346-348.

Hughes, E. W. (1964). Familial interstitial pulmonary fibrosis. Thorax, 19, 515-525.

Humphreys, G. S. (1965). Chronic diffuse progressive interstitial pulmonary fibrosis in a child. West Indian Medical Journal, 14, 18-21.

Ivemark, B. I., and Wallgren, C. G. (1962). Diffuse interstitial pulmonary fibrosis (Hamman-Rich syndrome) in infancy. Acta Paediatrica, Suppl. 135, 97.

Johnston, . D. I. (1973). Persistent diarrhoea, eosinophilia, erythema annulare and fibrosing alveolitis in a female infant. Proceedings of the Royal Society of Medicine, 66, 346-348.

Kapanci, Y., and Chauvet, M. (1967). La pneumonie desquamative interstitielle. Schweizerische Medizinische Wochenschrift, 97, 1199-1208.

Kubašta, M., Krejčí, J., Janíček, M., and Rozmaričová, K. (1958). Diffuse interstitial pulmonary fibrosis. Rozhledy $V$ Tuberkulose, 18, 19-28.

Liebeschuetz, H. J., and Butler, N. R. (1965). HammanRich syndrome with encephalitis, hepatosplenomegaly, anaemia and thrombocytopenia. Proceedings of the Royal Society of Medicine, 58, 692-693. 
Liebow, A. A., Steer, A., and Billingsley, J. G. (1965). Desquamative interstitial pneumonia. American Journal of Medicine, 39, 369-404.

Livingstone, J. L., Lewis, J. G., Reid, L., and Jefferson, K. E. (1964). Diffuse interstitial pulmonary fibrosis: a clinical, radiological and pathological study based on 45 patients. Quarterly Journal of Medicine, 33, 71-103.

McCombs, R. P. (1972). Diseases due to immunologic reactions in the lungs. New England Journal of Medicine, 286, 1245-1252.

Mann, T. P. (1959). Diffuse progressive interstitial fibrosis of lungs in infancy. Proceedings of the Royal Society of Medicine, 52, 638-639.

Mann, T. P. (1965). Diffuse progressive interstitial fibrosis of lungs in infancy. Postgraduate Medical Journal, 41, 687-696.

Midwinter, R. E., Apley, J., and Burman, D. (1966). Diffuse interstitial pulmonary fibrosis with recovery. Archives of Disease in Childhood, 41, 295-298.

Nagaya, H., Elmore, M., and Ford, C. D. (1973). Idiopathic interstitial pulmonary fibrosis. American Review of Respiratory Diseases, 107, 826-830.

O'Shea, P. A., and Yardley, J. H. (1970). The Hamman-Rich syndrome in infancy: report of a case with virus-like particles by electron microscopy. Johns Hopkins Medical Journal, 126, 320-336.

Patchefsky, A. S., Israel, L. H., Hoch, W. S., and Gordon, G. (1973). Desquamative interstitial pneumonia: relationship to interstitial fibrosis. Thorax, 28, 680-693.

Poon, M. C., Epstein, S. W., and Sepp, H. (1973). Immunofluorescent staining of lung biopsy in fibrosing alveolitis. Canadian Medical Association Journal, 108, 734-739.

Radice, C., Conconi, G., Quarti, M. L., and Botturi, M. (1969). Pneumopatia interstiziale desquamativa. Minerva Pediatrica, 21, 29-38.

Rosenow, E. C., O'Connell, E. J., and Harrison, E. G. (1970). Desquamative interstitial pneumonia in children. Report of two cases. American Journal of Diseases of Children, 120, 344-348.

Rubin, E. H., and Lubliner, R. (1957). The Hamman-Rich syndrome: review of the literature and analysis of 15 cases. Medicine, 36, 397-463.

Scadding, J. G. (1964). Fibrosing alveolitis. (Letters.) British Medical Journal, 2, 686; 941.

Scadding, J. G. (1970). Lung biopsy in the diagnosis of diffuse lung disease. British Medical Journal, 2, 557-564.
Scadding, J. G., and Hinson, K. F. W. (1967). Diffuse fibrosing alveolitis (diffuse interstitial fibrosis of the lungs). Correlation of histology at biopsy with prognosis. Thorax, 22, 291-304.

Schneider, R. M., Nevius, D. B., and Brown, H. Z. (1967). Desquamative interstitial pneumonia in a four-year-old child. New England Journal of Medicine, 277, 1056-1058.

Stack, B. H. R., Choo-Kang, Y. G. J., and Heard, B. E. (1972). The prognosis of cryptogenic fibrosing alveolitis. Thorax, 27, 535-542.

Stringer, R. J., Stiles, Q. R., Lindesmith, G. C., Meyer, B. W., and Jones, J. C. (1968). Use of lung biopsy in diagnosis of pulmonary lesions in children. American Surgeon, 34, 810-812.

Tan, K. L., Tee, O. K., and Poh, W. K. (1974). Pulmonary interstitial fibrosis in an infant. Journal of the Singapore Paediatric Society, 16, 42-46.

Toyama, W. M., Reyes, C. N., Lawton, B. R., and Sautter, R. D. (1971). Open lung biopsy in infants and children. Archives of Surgery, 103, 195-198.

Turner-Warwick, M. (1968). Fibrosing alveolitis and chronic liver disease. Quarterly Journal of Medicine (New Series), 37, 133-149.

Turner-Warwick, M. (1971/72). Cryptogenic fibrosing alveolitis. British Journal of Hospital Medicine, 7, 697-704.

Turner-Warwick, M. (1974). A perspective view on widespread pulmonary fibrosis. British Medical Journal, 2, 371-376.

Vaněk, J. (1954). Interstitielle nicheitrige Pneumonie. Zentralblatt für Allgemeine Pathologie und Pathologische Anatomie, 92, 405-416.

Vestermark, S. (1961). Hamman-Rich syndrome. Acta Paediatrica, 50, 404-410.

Weng, T. R., Levison, H., Wentworth, P., Simpson, J., and Moes, C. A. F. (1968). Open lung biopsy in children. American Review of Respiratory Diseases, 97, 673-684.

Whitcomb, M. E., Schwarz, M. I., Charles, M. A., and Larson, P. H. (1970). Interstitial fibrosis after Pneumocystis carinii pneumonia. Annals of Internal Medicine, 73, 761-765.

Zaręba, J., and Pyda, E. (1966). Zwłoknienie Płuc pokrztuscowe u chłopca 10. Letniego. Pediatria Polska, 41, 97-99.

Correspondence to Prof. D. Hull, Department of Child Health, University Hospital and Medical School, Clifton Boulevard, Nottingham NG7 2UH. 